\title{
Microextraction and Gas Chromatography/Mass Spectrometry for improved analysis of geosmin and other fungal "off" volatiles in grape juice
}

\author{
H. Morales-Valle *, L.C. Silva, R.R.M. Paterson, J.M. Oliveira, A. Venâncio, N. Lima \\ IBB - Institute for Biotechnology and Bioengineering, Centre of Biological Engineering, University of Minho, Campus de Gualtar, 4710-057 Braga, Portugal
}

\section{A R T I C L E I N F O}

\section{Article history:}

Received 19 February 2010

Received in revised form 13 July 2010

Accepted 13 July 2010

Available online 22 July 2010

\section{Keywords}

Botrytis cinerea

Earthy odours

Gas Chromatography-Mass Spectrometry

Geosmin

Penicillium expansum

Solid Phase Microextraction

\begin{abstract}
A B S T R A C T
Geosmin is a volatile fungal metabolite with an earthy aroma produced in grape products from rotten grapes. The accumulation of geosmin in grapes is caused by the interaction of Botrytis cinerea and Penicillium expansum. Solid Phase Microextraction (SPME) has great utility for collecting volatile compounds in wine. However, contamination with earthy odours may have occurred previously in the must and novel methods are required for this commodity. In the present report, several parameters of the SPME were evaluated to optimize geosmin extraction. The method permitted quantification of geosmin and other fungal volatiles by Gas Chromatography-Mass Spectrometer (GC-MS) at very low concentrations. Limits of detection and quantification $\left(L_{\mathrm{D}}\right.$ and $L_{\mathrm{Q}}$ ) for geosmin were $4.7 \mathrm{ng} \mathrm{L}^{-1}$ and $15.6 \mathrm{ng} \mathrm{L}^{-1}$ respectively. The RSD was $4.1 \%$ and the recovery rates ranged from $115 \%$ to $134 \%$. Uniquely, haloanisoles were analyzed by using only one internal standard (2,3,6-trichloroanisole) thus avoiding the synthesis of deuterated anisole analogues that are used as internal standard in other methods. The method was used for the analysis of grape juice samples inoculated with $B$. cinerea and P. expansum. Geosmin and methylisoborneol were the compounds that appeared to contribute most to earthy odours, although other fungal compounds which are claimed to cause earthy or mouldy off-odours were detected (e.g. 1-octen-3-ol and fenchol).
\end{abstract}

(c) 2010 Elsevier B.V. All rights reserved.

\section{Introduction}

Geosmin is an aromatic volatile metabolite with an earthy smell which is detected in grape products made with rotten grapes (La Guerche et al., 2005). It is a common metabolite from fungi (Paterson et al., 2007). La Guerche et al. (2005) demonstrated that the accumulation of geosmin in grape juice and crushed grapes is caused by Botrytis cinerea and Penicillium expansum by extraction of must from rotten grapes and analysis by Gas Chromatography-Mass Spectrometry (GC-MS). B. cinerea causes grey rot of grapes and $P$. expansum causes blue rot of apples and produces the mycotoxin patulin. The authors reported that some isolates of $B$. cinerea induced the productions of geosmin by P. expansum. La Guerche et al. (2006) discovered that $22 \%$ of $B$. cinerea strains isolated from the centre of grape bunches induced high geosmin production and demonstrated the positive impact of the presence of ammonium and amino-acid deficiencies on geosmin accumulation.

In addition, methylisoborneol (MIB) and 1-octen-3-ol are produced by $B$. cinerea. The former has a similar aroma to geosmin and the latter has a mushroom taint (Paterson et al., 2007). Other compounds of fungal origin with earthy, muddy or mushroom odour

\footnotetext{
* Corresponding author. Tel.: +351 253604 400; fax: +351253678 986. E-mail address: hmorales@deb.uminho.pt (H. Morales-Valle).
}

are fenchone, fenchol and haloanisoles, which can also be detected in musts or crushed grapes (Boutou and Chatonnet, 2007).

The first reference regarding analysis of geosmin in wines is Darriet et al. (2001). The authors extracted with pentane some wines with a strong earthy odour which were analyzed by Gas ChromatographyOlfactometry (GC-O), a procedure involving smelling the fractions. These analyses revealed the presence of only one strong odorous fraction, reminiscent of the earthy odours in the wines and the relevant metabolite in the fraction had the same retention time as geosmin. GC-O has become the method of choice for geosmin analyses. The smelling of grape juices and wines for volatile compound is discouraged from issues of Health and Safety by the current authors, because of the known toxicity of some fungal secondary metabolites (Paterson et al., 2007). In addition, the method has a subjective quality from the variable responses humans have to smells.

Solid Phase Microextraction (SPME) was first developed by Arthur and Pawliszyn (1995). Nilsson et al. (1996) reported that headspace SPME (HS-SPME) was effective at collecting volatile organic compounds emitted from Penicillium. Isopentyl alcohol, 1-octen-3-ol, 3octanone, 3-octanol, MIB and geosmin were detected by this method. Since then, several assays were carried out to detect and quantify geosmin, MIB and other volatiles in water. Saito et al. (2008) optimized the method by assessing parameters of the extraction such as fibre coating, temperature and time of extraction, agitation and $\mathrm{pH}$. Boutou and Chatonnet (2007) analyzed 20 compounds causing off-flavours in wine by HS-SPME followed by GC-GCMS. 
Several factors were evaluated in order to optimize the extraction (e.g. type of fibre, dilution of sample, $\mathrm{pH}$, temperature and time of extraction). They optimized the extraction of 2-methoxy-3,5dimethylpyrazine (2M35DP) and achieved a linear, specific, accurate and repeatable method.

Grape juice can be consumed directly or fermented into wine. However, no reports are available regarding HS-SPME/GC-MS analysis of volatile fungal compounds in grape juice per se. This is surprising given the earthy aromas that may originate at this stage. The composition of must is dramatically different from that of wine, with the absence of ethanol being an obvious feature, which may cause variations in solubility and volatility of some fungal volatile metabolites (FVM.) Also, the compounds causing earthy off-odours in musts may be different from that in wine and the off-odours may be better controlled by determination in musts before fermentation. Methods for the analysis of earthy volatile compounds in wine may not be suitable for musts and so a novel procedure is required. In the present article, HS-SPME extraction and GC/MS were employed for analysis of fungal volatiles in grape juice as a model for musts.

\section{Materials and methods}

\subsection{Reagents and materials}

Geosmin and MIB (100 $\mathrm{mg} \mathrm{L}^{-1}$ in methanol); 1-octen-ol (98\% purity); 2,4,6-trichloroanisole (99.9\%) tribromoanisole (99.9\%), fenchol (98\%); fenchone (99\%) and methyl-4-pentan-2-ol (97\%) were supplied by Sigma Aldrich (USA). 2,3,4,6-Tetrachloroanisole (99\%) was supplied by Ultra Scientific (USA). Pentachloroanisole (99\%) was supplied by ChemService (USA) and 2,3,6-trichloroanisole (99\%) was supplied by Honeywell Riedel-de Haën (Germany). Absolute ethanol (Panreac, Spain) was used for analyte and internal standard solutions. The water was MilliQ grade. The fibre (Sigma Aldrich, USA) was coated with Divinylbenzene/Carboxen/Polydimethylsiloxane (DVB/CAR/PDMS).

Thirty strains of $B$. cinerea were obtained from (i) Vinhos Verdes vineyards in the Minho region of Portugal and (ii) Rias Baixas vineyards in the South of Galicia, Spain both with the "Appellation of Origin" standard. The sampling was carried out in the zone in which both wine regions are almost contiguous, separated only by the river Minho/Miño. The attack of $B$. cinerea in both regions is quite common, probably influenced by the high rainfalls of the regions. P. expansum (MUM 00.02) was obtained from the culture collection, Micoteca da Universidade do Minho (Braga, Portugal), and MUM is the accession prefix of the culture collection.

A significantly adapted method that Boutou and Chatonnet (2007) employed for wine was used to analyze for volatile compounds produced by the inoculation of $B$. cinerea and $P$. expansum in grape juice medium (GJM). The metabolites studied were haloanisoles [2,4,6,-trichloroanisole (2,4,6-TCA); 2,3,4,6-tetrachloroanisole (TeCA); 2,4,6-tribromoanisole (TBA); pentachloroanisole (PCA)]; 1 octen-3-ol; methylisoborneol (MIB); geosmin; fenchone and fenchol. Variations in $\mathrm{pH}$, time of extraction, temperature, and $\mathrm{NaCl}$ concentration were evaluated for extraction optimization. The effect of ethanol addition was also assessed as a model system for wine. Geosmin was employed to optimize the extraction.

For assays involving natural contaminated samples, $3.2 \mathrm{~g}$ of $\left(\mathrm{NH}_{4}\right)$ $\mathrm{H}_{2} \mathrm{PO}_{4}$ was dissolved in $100 \mathrm{~mL}$ of MilliQ water. Grape extract was prepared as follows: $1 \mathrm{~kg}$ of grapes was crushed in $1 \mathrm{~L}$ of water, boiled for $2 \mathrm{~h}$ and filtered. The volume was brought to $1 \mathrm{~L}$ and sterilized at $121^{\circ} \mathrm{C}$ for $15 \mathrm{~min}$ (Santos et al., 2002). If necessary, the grape extract was frozen or stored at $5{ }^{\circ} \mathrm{C}$ for a maximum of two weeks. Any unused portion was discarded. To prepare the GJM, $200 \mathrm{~mL}$ of the extract was added to $800 \mathrm{~mL}$ of sterilized water. Membrane filters $(0.45 \mu \mathrm{m})$ (Whatman, United Kingdom) were used to sterilize the medium after $B$. cinerea incubation.

\subsection{Gas Chromatography-Mass Spectrometry}

A Varian 4000 GC/MS (Varian Inc. CA, USA) with ion trap and mass spectrometer was used with a Varian FactorFour VF-5 ms capillarity column $(20 \mathrm{~m} \times 0.15 \mathrm{~mm} \mathrm{df}=0.15 \mu \mathrm{m})$. The temperature of the injector was $270{ }^{\circ} \mathrm{C}$ adjusted to splitless mode. The carrier gas was helium at a flow of $1.5 \mathrm{~mL} \mathrm{~min}^{-1}$. The temperature of the oven started at $50{ }^{\circ} \mathrm{C}$ and was held for $2 \mathrm{~min}$. Then the temperature was increased $3{ }^{\circ} \mathrm{C} / \mathrm{min}$ to achieve $190{ }^{\circ} \mathrm{C}$ (total time $48.67 \mathrm{~min}$ ) followed by $50{ }^{\circ} \mathrm{C} / \mathrm{min}$ to achieve $320^{\circ} \mathrm{C}$ (total time $53.27 \mathrm{~min}$ ).

The analytes and internal standards were spiked into $10 \mathrm{~mL}$ of GJM and subjected to HS-SPME and GC/MS in full mode detection $(\mathrm{m} / \mathrm{z}$ from 20 to 1000). Based on the retention times described in Boutou and Chatonnet (2007), the chromatograms and spectra thus obtained were compared to a control sample of GJM.

\subsection{Extraction method and optimization}

All the assays in this section were repeated three times. The influence of a) $\mathrm{NaCl}$ saturation, b) $\mathrm{pH}, \mathrm{c}$ ) ethanol, d) temperature of extraction and e) time of extraction was evaluated. For this purpose, $10 \mathrm{~mL}$ of GJM was spiked with geosmin standard to a concentration of $100 \mathrm{ng} \mathrm{L}^{-1}$ and subjected to HS-SPME under the different conditions tested. The samples were poured into a $15 \mathrm{~mL}$ screwcapped vial containing a septum. A Teflon coated magnetic stirrer was placed in the vial. The vial was placed on a magnetic heater and stirred at $1000 \mathrm{rpm}$ for $45 \mathrm{~min}$. Because it is not possible to control the temperature in the vial where extraction is being performed, another vial with GJM was placed on the heater and stirred at $1000 \mathrm{rpm}$. The temperature was recorded in this vial. Two minutes after the target temperature was achieved in the control vial, the fibre was exposed to the headspace. The position of the fibre in the headspace must be constant. The end of the fibre was positioned in the last third of the headspace. After extraction, the fibre was placed in the injector of the GC/MS at $270{ }^{\circ} \mathrm{C}$ for $5 \mathrm{~min}$. The peak areas of geosmin for each condition were recorded. The parameter that significantly maximized the peak area was considered as the optimum condition of extraction. Each condition was tested in triplicate and the results obtained (i.e. the area of the geosmin peaks) were subjected to ANOVA tests.

Five experiments were undertaken: a) geosmin was added to GJM at the concentration mentioned above. The effect of $\mathrm{NaCl}$ was tested by saturating GJM with $\mathrm{NaCl}$. Ten $\mathrm{mL}$ of the spiked $\mathrm{NaCl}$ saturated medium was subjected to HS-SPME extracted for $45 \mathrm{~min}$ at $50{ }^{\circ} \mathrm{C}$ and analyzed. The results were compared with GJM. b) The influence of the $\mathrm{pH}$ of the sample was tested at $\mathrm{pH} 3.4$ and $\mathrm{pH}$ 7. GJM was adjusted to $\mathrm{pH} 7$ with $0.1 \mathrm{~mol} \mathrm{~L}^{-1} \mathrm{NaOH}$. c) The influence of ethanol was assessed by analyzing geosmin spiked GJM at $0,3,6$ and $12 \% \mathrm{v} / \mathrm{v}$ ethanol. d) Five temperatures of extraction (30, 45, 50, 60 and $70 \stackrel{\circ}{C}$ ) were assayed. The extraction was performed for $45 \mathrm{~min}$. Finally, e) the influence of extraction time was evaluated for $10,20,30,40,50$ or $60 \mathrm{~min}$ at $50{ }^{\circ} \mathrm{C}$.

\subsection{Calibration curves and parameters of the method}

Standards were at the following concentrations in ethanol: haloanisoles $\left(1 \mu \mathrm{g} \mathrm{L}^{-1}\right)$; geosmin and MIB $\left(20 \mu \mathrm{g} \mathrm{L}^{-1}\right)$ and 1-octen3-ol, fenchone and fenchol $\left(1 \mathrm{mg} \mathrm{L}^{-1}\right)$. Internal standard solutions were at: $500 \mu \mathrm{g} \mathrm{L}^{-1}$ for $4 \mathrm{M} 2 \mathrm{P}$ and $25 \mu \mathrm{g} \mathrm{L}^{-1}$ for $2,3,6$-TCA.

The calibration curves and the other parameters (i.e. correlation coefficient of the curve $\left(r^{2}\right)$, sensitivity, limit of detection $\left(L_{\mathrm{D}}\right)$, limit of quantification $\left(L_{\mathrm{Q}}\right)$, repeatability (RSD \%), and recovery rates) for each compound were assessed by adding different volumes of analyte solution and $5 \mu \mathrm{L}$ of internal standard solution to $10 \mathrm{~mL}$ of GJM. Each sample was subjected to HS-SPME at optimum conditions and GC/MS was performed. 
Table 1

Characteristic ions of the analytes and internal standards.

\begin{tabular}{|c|c|c|}
\hline Compound & Ret. time (min) & Charact. ions $(\mathrm{m} / \mathrm{z})$ \\
\hline 4M2P & 2.7 & $45 ; 69$ \\
\hline 1-Octen-3-ol & 9.0 & $\overline{69} ; 95$ \\
\hline Fenchone & 13.4 & $\overline{81}$ \\
\hline Fenchol & 14.7 & $\overline{81} ; 121$ \\
\hline MIB & 18.6 & $\overline{95}$ \\
\hline $2,4,6-\mathrm{TCA}$ & 23.8 & $1 \overline{67} ; 195 ; 210$ \\
\hline $2,3,6$ TCA & 25.7 & $\overline{167} ; 197 ; 212$ \\
\hline Geosmin & 27.0 & $\overline{112}$ \\
\hline $\mathrm{TeCA}$ & 31.3 & $203 ; 202 ; 246 ; 248$ \\
\hline TBA & 34.8 & $329 ; 344 ; 347$ \\
\hline PCA & 38.3 & $\overline{237} ; 280$ \\
\hline
\end{tabular}

The ions are ordered by abundance.

Those which are underlined were used for quantification.

\subsection{Analysis of naturally contaminated samples}

B. cinerea isolates were inoculated in Potato Dextrose Agar plates (PDA) (Oxoid, United Kingdom) and were incubated for 7 days at $25^{\circ} \mathrm{C}$ in the dark. A suspension of $10^{5}$ spores $\mathrm{mL}^{-1}$ of each isolate was prepared in sterile water containing Tween $80(0.005 \% \mathrm{v} / \mathrm{v})$. Each suspension ( $1 \mathrm{~mL}$ ) was inoculated in $50 \mathrm{~mL}$ of GJM contained in screwcapped plastic containers suitable for microbiological culturing. Incubation was at $25^{\circ} \mathrm{C}$ for 14 days.

The mycelium of $B$. cinerea was removed and the medium was resterilized by filtration and poured into sterile plastic containers. A suspension of $10^{6}$ conidia $\mathrm{mL}^{-1}$ of $P$. expansum MUM 00.02 was obtained from a PDA plate inoculated one week before and incubated at $25{ }^{\circ} \mathrm{C}$. Each of the containers was amended with $1 \mathrm{~mL}$ of the solution of $\left(\mathrm{NH}_{4}\right) \mathrm{H}_{2} \mathrm{PO}_{4}$ to obtain a concentration of $500 \mathrm{mg} \mathrm{L}^{-1} \mathrm{NH}_{4}^{+}$, to replace the nitrogen utilised by $B$. cinerea [1]. Finally, the flasks were inoculated with $20 \mu \mathrm{L}$ of the $P$. expansum conidial suspension and incubated for 3 days at $25{ }^{\circ} \mathrm{C}$.

The $P$. expansum biomass was removed and the media were filtered to clarity. Ten $\mathrm{mL}$ of each sample amended with $5 \mu \mathrm{L}$ of internal standard solution was subjected to HS-SPME at optimum conditions and analyzed.

\section{Results and discussion}

\subsection{Optimization of the extraction}

The retention times of the standards were equal to those described by Boutou and Chatonnet (2007). The ions detected were also similar although the abundance differed (Table 1 ) thus, the ions used for detection and quantification were altered in the present study. These differences may be due to the use of different matrices and analytical conditions which adds to the novelty of the present method. The ions

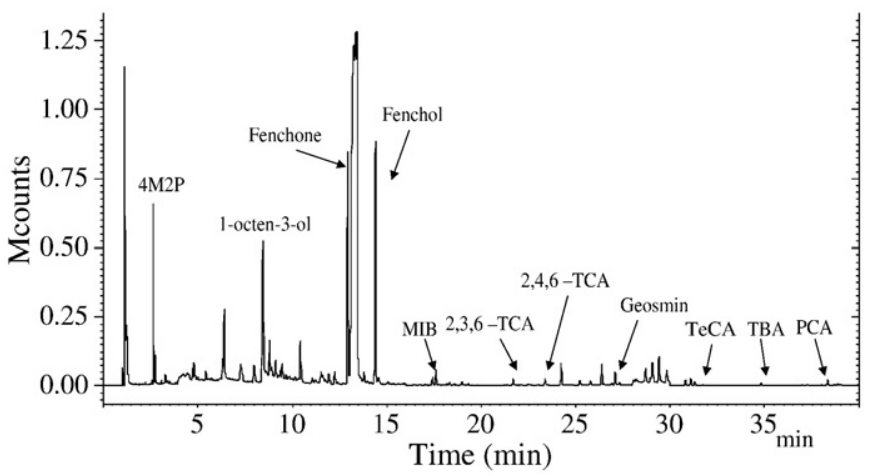

Fig. 1. Chromatogram in SIS mode detection of a sample of grape juice medium spiked with $100 \mu \mathrm{L}$ of analyte solution and $5 \mu \mathrm{L}$ of internal standard solution.

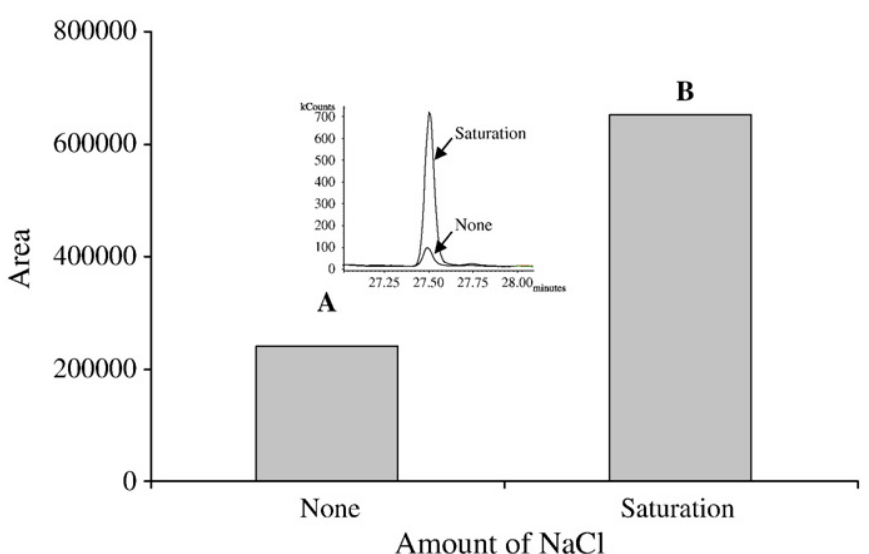

Fig. 2. Effect of $\mathrm{NaCl}$ saturation on geosmin extraction.

$\mathrm{m} / \mathrm{z} 112.1$ and 95 were the most abundant for geosmin and MIB respectively and were used for quantification (Saito et al., 2008). A typical SIS-GC chromatogram of a sample spiked with $100 \mu \mathrm{L}$ of analyte solution is presented in Fig. 1.

The peak areas of $\mathrm{NaCl}$ saturated samples were significantly higher than unaltered samples $(P<0.001)$ (Fig. 2). However, pH at $\mathrm{NaCl}$ saturation had no effect on the efficiency of the microextraction (data not shown). Thus, the subsequent $\mathrm{pH}$ of the samples was that of GJM (i.e. pH 3.4). The presence of ethanol in the sample influenced considerably the extraction of geosmin. As shown in Fig. 3, the tendency was a linear decrease in extraction of geosmin with increased ethanol $\left(r^{2}=0.95\right)$. The ethanol may saturate the headspace thus reducing volatilization of geosmin (and other compounds). Again, this indicates the uniqueness and advantages of the present method as it is designed for musts rather than wine.

Temperature and time of extraction resulted in considerable variation in the data obtained. However, a tendency could be observed. The maximum extraction of geosmin was obtained at between 45 and $50{ }^{\circ} \mathrm{C}$. (Fig. $4 \mathrm{a}$ ). The peak of MIB was more defined and slightly higher at $50{ }^{\circ} \mathrm{C}$ and this temperature was chosen as the optimum. The maximum extraction of geosmin tended to be at $30 \mathrm{~min}$ (Fig. 4b). These optimum conditions are summarized in Table 2. All subsequent assays were performed at these conditions.

\subsection{Calibration curves and parameters of the method}

The parameters of the method are shown in Table 3. In general, these are comparable to those reported in Boutou and Chatonnet (2007) and Saito et al. (2008). The variability, measured as RSD (\%), is

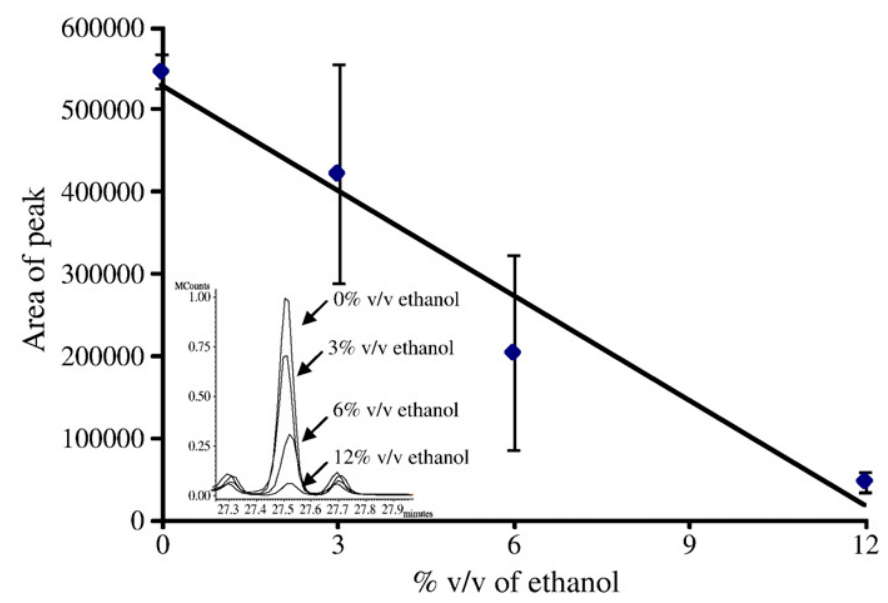

Fig. 3. Effect of ethanol content on geosmin extraction. 

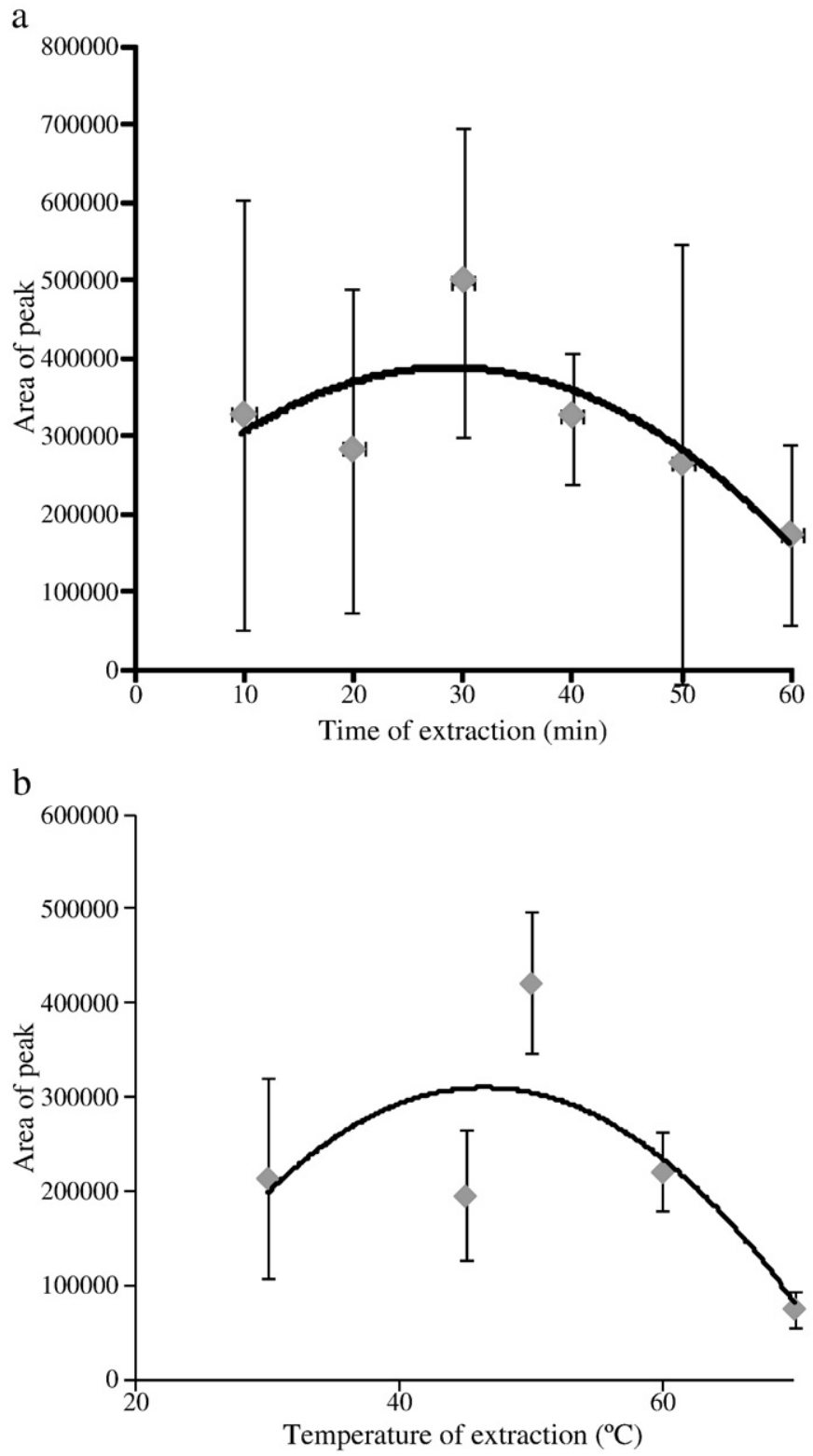

Fig. 4. Effect of parameters of extraction in extraction of geosmin. a) Effect of time of extraction. b) Effect of temperature of extraction.

improved compared to that reported in Boutou and Chatonnet (2007). In general, automation of HS-SPME is incomplete and thus, parameters such as temperature or position of the fibre in the headspace are hard to measure precisely. This may explain the variability among the replications. Importantly, the $L_{\mathrm{D}} \mathrm{S}$ of the analytes assayed are below the olfactory perception threshold (OPT) described in Boutou and Chatonnet (2007).

It was possible to lower the $L_{\mathrm{Q}}$ and the RSD (\%) for geosmin and MIB by optimizing the sample preparation for HS-SPME. The method

Table 2

Optimum values of extraction for the parameters assayed.

\begin{tabular}{ll}
\hline Parameter & Optimum value \\
\hline $\mathrm{NaCl}$ content & Saturation \\
$\mathrm{pH}$ & 3.4 \\
Ethanol content & None \\
Temperature & $50{ }^{\circ} \mathrm{C}$ \\
Time & $30 \mathrm{~min}$ \\
\hline
\end{tabular}

was used to detect most of the other relevant compounds of fungal origin present in grape juice. Significantly, the quantification of geosmin and MIB is actually improved. Other benefits include potential health and safety improvements compared to GC-O methods and more objective results from removing the requirement for olfactory detection by humans.

Furthermore, the results obtained are acceptable in most cases for haloanisoles. Although the $L_{\mathrm{D}}$ and $L_{\mathrm{Q}}$ were higher than those in Boutou and Chatonnet (2007), the importance of such compounds is lower in musts than in wines since they do not cause earthy odours in musts and were detected only in traces. However, the (i) $r^{2}$ of the calibration curve, (ii) RSD (\%) and (iii) recovery rate at lower concentrations were not satisfactory in the case of TeCA. Thus, the method is qualitative for this compound. Finally, it is a unique feature of our method that it is not required to synthesize the deuterated chloroanisole analogue, because 2,3,6-TCA is used as internal standard for all the anisoles.

\subsection{Analysis of naturally contaminated samples}

Twenty seven \% of the samples yielded geosmin which is similar to that reported in La Guerche et al. (2007) for crushed rotten grapes. Geosmin was below the $L_{\mathrm{Q}}$ in one sample (data not shown) and two of them accumulated geosmin above the OPT of wine $\left(50 \mathrm{ng} \mathrm{L}^{-1}\right)$ (Fig. 5) [all the OPTs referred to subsequently are from Boutou and Chatonnet (2007)]. All the samples yielded MIB (average $44.26 \mathrm{ng} \mathrm{L}^{-1}$ ) and in $30 \%$, MIB accumulated above the OPT in wine of $55 \mathrm{ng} \mathrm{L}^{-1}$. MIB is known to be synthesized consistently by $B$. cinerea which explains the presence of this metabolite. Traces of fenchone were detected in $47 \%$ of the samples (OPT in wine $=500 \mu \mathrm{L} \mathrm{L}^{-1}$ ). Also, $87 \%$ of the samples were fenchol positive (OPT in wine $=50 \mu \mathrm{g} \mathrm{L}^{-1}$ ), although none yielded amounts above the $L_{\mathrm{Q}}$. Interestingly, La Guerche et al. (2006) reported similar concentrations of both compounds in rotten grapes and musts made with rotten grapes. In that assay, the musts were extracted with distilled pentane and analyzed by GC-O.

All the samples yielded 1-octen-3-ol, although in low quantities (average $3.84 \mu \mathrm{g} \mathrm{L}^{-1}$; the OPT in wine $=40 \mu \mathrm{g} \mathrm{L}^{-1}$ ). 1-Octen-3-ol is a consistent by-product of the metabolic activity of $B$. cinerea (Yunome et al., 1981) indicating the compound was produced by the fungus.

Traces of all the haloanisoles (i.e. TCA, TeCA, PCA and TBA) were detected in $57 \%$ of the samples. These results may demonstrate that the contamination of wines with haloanisoles occur not only in the cellar or by means of tainted corks, but also in the first steps of wine making process in the vineyard.

\section{Conclusion}

The analysis of compounds causing earthy odour in musts require novel methods such as those described herein. The composition of must is dramatically different from that of wine, which may change the solubility and volatility of FVMs. The current method is focused in the detection of earthy odorants that are present in grape must and that may subsequently cause off-odours in wines, hence allowing remedial action to be taken. In Boutou and Chatonnet (2007), optimization corresponded to the maximum extraction of 2M35DP, which is a compound with a "corky" odour found from contaminated cork and thus it may not be present in musts with earthy odour. Consequently, the parameters of this method were optimized by focusing on geosmin, which is known to be present in rotten grape bunches. Moreover, the parameters of the extraction were adjusted for samples without ethanol from fermentation. As a consequence, $\mathrm{pH}$, time and temperature of extraction during SPME differed from that reported in Boutou and Chatonnet (2007) and were suitable for musts. This permitted a higher volatilization of the compound in the headspace and improved geosmin extraction. Such high concentrations of geosmin in the headspace led to more accurate detection and an improved RSD (\%). A similar situation was achieved for MIB. 
Table 3

Parameters of the method.

\begin{tabular}{|c|c|c|c|c|c|c|c|c|c|c|}
\hline & & $\begin{array}{l}\text { Geosmin } \\
\left(\mathrm{ng} 1^{-1}\right)\end{array}$ & 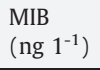 & $\begin{array}{l}\text { 1-octen-3-ol } \\
\left(\mu \mathrm{g} 1^{-1}\right)\end{array}$ & $\begin{array}{l}\text { Fenchone } \\
\left(\mu \mathrm{g} 1^{-1}\right)\end{array}$ & $\begin{array}{l}\text { Fenchol } \\
\left(\mu \mathrm{g} 1^{-1}\right)\end{array}$ & $\begin{array}{l}2,4,6-\mathrm{TCA} \\
\left(\mathrm{ng} \mathrm{1^{- }}\right)\end{array}$ & $\begin{array}{l}\text { ТeCA } \\
\left(\text { ng } 1^{-1}\right)\end{array}$ & $\begin{array}{l}\text { TBA } \\
\left(\text { ng } 1^{-1}\right)\end{array}$ & $\begin{array}{l}\text { PCA } \\
\left(\operatorname{ng} 1^{-1}\right)\end{array}$ \\
\hline$r^{2}$ & & 0.995 & 0.989 & 0.984 & 0.986 & 0.994 & 0.999 & 0.977 & 0.991 & 0.995 \\
\hline Sensitivity & & 0.02 & 0.01 & 0.51 & 0.07 & 0.26 & 0.15 & 0.08 & 0.08 & 0.13 \\
\hline$L_{\mathrm{D}}$ & & 4.7 & 3.8 & 1.2 & 1.1 & 0.7 & 3.0 & 2.2 & 1.3 & 2.7 \\
\hline$L_{\mathrm{Q}}$ & & 15.6 & 12.5 & 2.8 & 3.5 & 2.3 & 9.6 & 7.1 & 4.2 & 8.7 \\
\hline $\mathrm{RSD}(\%)$ & & 4.1 & 8.1 & 2.7 & 3.2 & 9.0 & 5.8 & $>10$ & 3 & 1.3 \\
\hline \multirow[t]{3}{*}{ Recovery $^{1}$} & a) & 134 & 112 & 123 & 125 & 70 & 112 & $<10$ & 3 & 1.3 \\
\hline & b) & 115 & 107 & 107 & 76 & 104 & 103 & 93 & 80 & 106 \\
\hline & c) & 115 & 105 & 113 & 82 & 84 & 86 & 84 & 86 & 83 \\
\hline
\end{tabular}

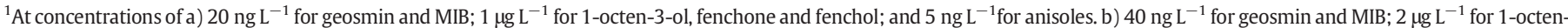
3-ol, fenchone and fenchol; and $10 \mathrm{ng} \mathrm{\textrm {L } ^ { - 1 }}$ for anisoles. c) $500 \mathrm{ng} \mathrm{L}^{-1}$ for geosmin and MIB; $25 \mu \mathrm{g} \mathrm{L}^{-1}$ for 1-octen-3-ol, fenchone and fenchol; and $25 \mathrm{ng} \mathrm{L}^{-1}$ for anisoles.

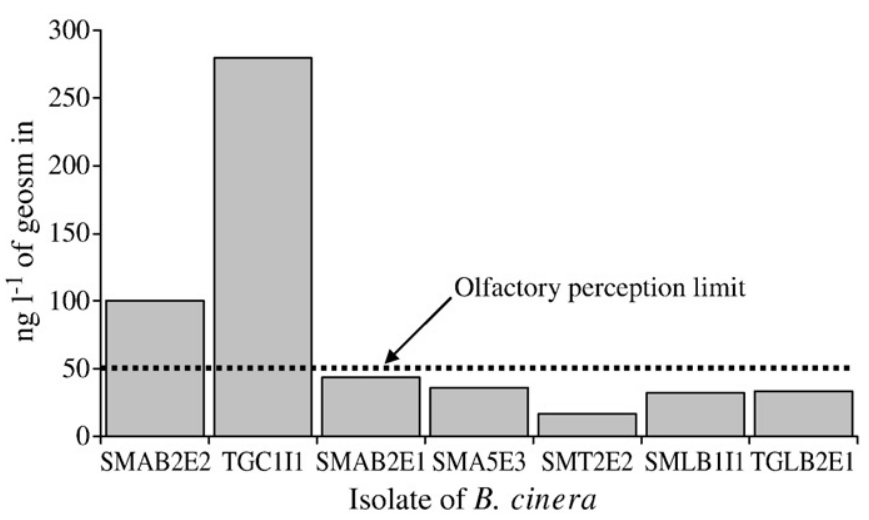

Fig. 5. Amount of geosmin in naturally contaminated samples.

Another important novelty of the present method is that it does not need the synthesis of deuterated haloanisole analogues since the quantification of most of the haloanisoles is performed with one internal standard (2,3,6-TCA) and thus is straight forward and economical. Although the $L_{\mathrm{D}}$ and $L_{\mathrm{Q}}$ were higher than those in Boutou and Chatonnet (2007), the importance of such compounds is lower in musts than in wines since they do not cause earthy odours in musts and were detected only at trace levels. The compounds that cause earthy odour in naturally contaminated grape juice were geosmin and MIB as the other compounds were always in levels below the OPT. In conclusion, the method permitted the detection of fungal compounds that are responsible for earthy, muddy or "fungus" odours in naturally contaminated samples. This report relates the first detection of these volatiles in grape juice and the method provides highly significant improvements over the previous in terms of accuracy and safety.

\section{Acknowledgments}

The personnel of the vineyards who cooperated in supplying samples for this study are appreciated for their assistance. H. Morales-
Valle is grateful to the Portuguese Government. (Ministério da Ciência, Tecnologia e Ensino Superior; FCT Fundação para a Ciência e a Tecnologia. Grant ref. SFRH/BPD/38011/2007). R. Paterson is funded through FCT commitment to science framework Ref ${ }^{\mathrm{a}} \mathrm{C} 2008$-UMINHOCEB-02.

\section{References}

Arthur, C., Pawliszyn, J., 1995. Solid Phase Microextraction with thermal desorption using fused silica optical fibres. Anal. Chem. 62, 2145-2148.

Boutou, S., Chatonnet, P., 2007. Rapid headspace Solid Phase Microextraction/gas chromatographic/mass spectrometric assay for the quantitative determination of some of the main odorants causing off-flavours in wine. J. Chromatogr. A 1141, 1-9.

Darriet, P., Pons, M., Lamy, S., Dubourdieu, D., 2001. Identification and quantification of geosmin in wines, an earthy odorant contaminating wines. J. Agric. Food Chem. 48, 4835-4838.

La Guerche, S., Chamont, S., Blancard, D., Dubourdieu, D., Darriet, P., 2005. Origin of (-)geosmin on grapes: on the complementary action of two fungi. Antonie Leeuwenhoek 88, 131-139.

La Guerche, S., Brunhilde, D., Pons, M., Blancard, D., Darriet, P., 2006. Characterization of some mushrooms and earthy off-odors microbiallt induced by the development of rot on grapes. J. Agric. Food Chem. 54, 9193-9200.

La Guerche, S., De Senneville, L., Blancard, D., Darriet, P., 2007. Impact of the Botrytis cinerea strain and metabolism on $(-)$-geosmin production by Penicillium expansum in grape juice. Antonie van Leeuwenhoek 92, 331-341.

Nilsson, T. Larsen, T.O., Montanarella, L., Madsen, J.O., 1996. Application of head-space Solid Phase Microextraction for the analysis of volatile metabolites emitted by Penicillium species. J. Microbiol. Methods 25, 245-255.

Paterson, R.R.M., Venâncio, A., Lima, N., 2007. Why do food and drink smell like earth? In: Méndez-Vilas, A. (Ed.), Communicating Current Research and Educational Topics in Applied Microbiology, 2007. Formatex, Badajoz (Spain), pp. 120-128.

Saito, K., Okamura, K., Kataoka, H., 2008. Determination of musty odorants, 2methylisoborneol and geosmin, in environmental water by headspace Solid Phase Microextraction and gas chromatography-mass spectrometry. J. Chromatogr. A 1186, 434-437.

Santos, I.M., Abrunhosa, L., Venâncio, A., Lima, N., 2002. The effect of culture preservation on patulin and citrinin production by Penicillium expansum link Lett. Appl. Microbiol. 35, 272-275.

Yunome, H., Zenibayashi, Y., Date, M., 1981. Characteristic components of botrytised wine, sugar, alcohols, organic acids, and other factors. Hakkokogaku 59, 169-175. 